\title{
Densidade de plantio na produção hidropônica de minitubérculos de batata
}

\author{
Plant density in the hydroponical production of potato minitubers
}

\section{Jacso Dellai ${ }^{I}$ Dilson Antônio Bisognin ${ }^{\text {II* }}$ Jerônimo Luiz AndrioloII Nereu Augusto Streck ${ }^{\text {II }}$ Douglas Renato MüllerI Maurício Guerra Bandinelli ${ }^{I}$}

\section{RESUMO}

O objetivo deste trabalho foi determinar o efeito da densidade de plantio no crescimento da planta e na produção de minitubérculos de batata. O experimento foi conduzido no sistema hidropônico fechado, empregando areia como substrato, no interior de um abrigo telado. Minitubérculos (diâmetro entre 5 e 10mm) da cultivar "Macaca" foram plantados em 03 de setembro de 2004, em orifícios feitos na superfície do filme de polietileno que cobria o substrato. Os tratamentos consistiram das densidades de plantio de 25, 44, 100 e 400covas $\mathrm{m}^{-2}$. O delineamento experimental foi $o$ inteiramente casualizado, com três repetições. A água e os nutrientes foram fornecidos diariamente a todos os tratamentos, por meio de uma solução nutritiva completa. Aos 75 dias após o plantio, foram avaliadas a produtividade de tubérculos e a matéria seca. A matéria seca das plantas aumentou até a densidade de 100covas $\mathrm{m}^{-2}$. O número aumentou e a matéria seca média dos tubérculos diminuiu com o aumento da densidade de plantio. Os resultados indicam que a densidade de 100covas $\mathrm{m}^{-2}$ pode ser empregada para maximizar o número de tubérculos na produção hidropônica de batata.

Palavras-chave: Solanum tuberosum L., crescimento, produtividade, propagação de plantas.

\section{ABSTRACT}

The objective of this research was to determine the effect of plant density on plant growth and potato minituber yield. The experiment was carried out in a closed hydroponic system with sand as substrate in a greenhouse. Minitubers (diameter between 5 and 10mm) of the cultivar 'Macaca' were planted on September $3^{\text {rd }}$, 2004 in holes made on polyethylene film surface. The treatments were the densities of 25, 44, 100 and 400hills $\mathrm{m}^{-2}$. A completely randomized experimental design was used, with three replications. Water and nutrients were supplied daily with a standard nutrient solution. Tuber yield and dry matter production were determined at 75 days after planting. Dry mass of plants increased until 100hills $\mathrm{m}^{-2}$. Increasing plant density increased tuber number and decreased mean dry mass of tubers. Plant density of 100hills $\mathrm{m}^{-2}$ may be used to maximize tuber number in the hydroponical production of potato minitubers.

Key words: Solanum tuberosum L., growth, yield, plant propagation.

\section{INTRODUÇÃO}

O emprego de tubérculos-semente de alta qualidade fisiológica e fitossanitária é um dos aspectos mais importantes para a obtenção de elevadas produtividades da batata. A produção de batatasemente passa pela etapa da micropropagação in vitro, seguida de uma ou mais etapas de multiplicação de minitubérculos, que vêm sendo realizadas em sistemas hidropônicos (MEDEIROS et al., 2002). Por se tratar de tecnologia recente, há carência de informações a respeito das técnicas de manejo a serem adotadas para otimizar a produtividade de minitubérculos. Entre essas técnicas de manejo, a densidade de plantio afeta o crescimento e a produtividade da batata (RITTER et al., 2001).

A produção de biomassa depende da disponibilidade de radiação solar que chega à superfície da cobertura vegetal e da fração dessa radiação que é absorvida pelo dossel para realizar a fotossíntese. A

\footnotetext{
IPrograma de Pós-graduação em Agronomia, Universidade Federal de Santa Maria (UFSM), 97105-900, Santa Maria, RS, Brasil. IDepartamento de Fitotecnia, Centro de Ciências Rurais (CCR), UFSM, 97105-900, Santa Maria, RS, Brasil. E-mail: dilsonb@smail.ufsm.br. *Autor para correspondência.
} 
absorção da radiação solar depende principalmente do índice de área foliar (IAF), que aumenta assintoticamente com o crescimento e o desenvolvimento da cultura. A densidade de plantas afeta tanto o valor máximo do IAF atingido pela cultura, quanto o período de tempo decorrido desde a emergência até a estabilização do crescimento do IAF e, conseqüentemente, da absorção da radiação solar incidente (ANDRIOLO, 1999).

A produtividade das culturas agrícolas é o resultado da relação entre as fontes e os drenos pela utilização de fotoassimilados. No caso da batata, após o início da tuberização, os drenos principais são os tubérculos em crescimento. O período de tempo decorrido desde a emergência até a estabilização do IAF deve ter a duração mínima necessária para permitir o crescimento isométrico dos diferentes órgãos da planta (THORNLEY, 1998; SEGINER, 2004). Isso significa que a emissão e o crescimento dos tubérculos deve ocorrer posteriormente ao crescimento e desenvolvimento do aparato fotossintético. Quando a densidade de plantas é elevada, a estabilização do IAF pode ocorrer prematuramente e a área foliar de cada planta da cobertura vegetal pode ser insuficiente para atingir a produção mínima de assimilados necessários para o crescimento de tubérculos. Nesse caso, uma competição se estabelece entre o crescimento vegetativo e dos tubérculos, a qual provoca redução na produtividade e, em casos extremos, a morte da planta (PAPADOPOULOS \& PARARAJASINGHAM, 1997; HUTCHINGS \& JOHN, 2004).

Na produção de minitubérculos de batata, as relações entre fontes e drenos são modificadas porque os cultivos são finalizados logo no início da fase exponencial do crescimento dos tubérculos. Nesse caso, a demanda de assimilados para os drenos passa a depender principalmente do número de minitubérculos em crescimento. Se esse número é baixo, sobram assimilados, que estimulam o crescimento excessivo da parte vegetativa. Como a disponibilidade de assimilados é decorrente da absorção da radiação solar por unidade de área, é possível hipotetizar sobre o aumento da densidade de plantas como uma técnica de manejo para aumentar o número de drenos por unidade de área e, conseqüentemente, a produtividade de minitubérculos.

O objetivo deste trabalho foi avaliar o efeito da densidade de plantio no crescimento da planta e na produção de minitubérculos de batata em hidroponia.

\section{MATERIAL E MÉTODOS}

O experimento foi conduzido durante a primavera de 2004 (plantio em 03 de setembro), no interior de um abrigo telado de $150 \mathrm{~m}^{2}$, coberto com polietileno aditivado anti-UV de $200 \mu \mathrm{m}$ de espessura e paredes laterais revestidas com tela antiafídeos, localizado no Departamento de Fitotecnia da UFSM, Santa Maria, RS. Foi empregado o sistema hidropônico fechado com areia grossa como substrato, desenvolvido para a produção de minitubérculos de batata (ANDRIOLO, 2006). A solução nutritiva foi preparada com as quantidades de fertilizantes de, em mmol L-1 0,36 de $\mathrm{KH}_{2} \mathrm{PO}_{4} ; 1,17$ de $\mathrm{KNO}_{3} ; 2,18$ de $\mathrm{Ca}\left(\mathrm{NO}_{3}\right)_{2}$ e 0,71 de $\mathrm{MgSO}$. Os micronutrientes foram fornecidos nas concentrações de, em $\mathrm{mg} \mathrm{L}^{-1}, 0,03$ de Mo; 0,26 de B; 0,06 de Cu, 0,50 de Mn, 0,22 de Zn e 4,0 de quelato de Fe. As fertirrigações foram feitas diariamente durante 15 minutos, às 9 e 16h, desde o plantio até a constatação da cobertura foliar de toda a superfície de cultivo. Desse momento até o final do experimento, foram feitas quatro fertirrigações diárias, às $9,13,16$ e $18 \mathrm{~h}$.

Os tratamentos consistiram das densidades de plantio de 25, 44, 100 e 400covas $\mathrm{m}^{-2}$, obtidas respectivamente pelos espaçamentos de $20 \times 20,15 \times 15$, $10 \times 10$ e $5 \times 5 \mathrm{~cm}$ entre covas. O delineamento experimental foi o inteiramente casualizado, com três repetições. Cada repetição foi composta por fileiras de 1,25m de comprimento, dispostas na largura de 1,10m do canteiro, perfazendo uma área de $1,4 \mathrm{~m}^{2}$. As duas fileiras laterais de cada canteiro foram consideradas como bordaduras.

Ao ser constatado o início da senescência das folhas basais, aproximadamente 60 dias após o plantio, foi feita a coleta de 10 plantas em cada tratamento. Foram separadas as folhas, as hastes e as raízes de cada planta, as quais foram secadas em estufa de circulação forçada de ar, na temperatura de $60^{\circ} \mathrm{C}$, até obter massa constante entre pesagens consecutivas, para determinar a matéria seca. O IAF foi estimado a partir da coleta de 30 discos de área igual a $0,5026 \mathrm{~cm}^{2}$ de folhas representativas das diferentes partes do dossel vegetativo, os quais foram secos e pesados da mesma forma como os demais órgãos. Foi ajustada uma relação entre a matéria seca e a área dos discos, a qual foi utilizada para estimar o IAF (BENINCASA, 1988).

Aos 75 dias após o plantio, quando foi constatada a senescência de 50\% das folhas da planta, foi feita a colheita de todas as plantas das parcelas. Foi feita a contagem do número de plantas existentes e dos tubérculos produzidos na parcela e determinada a matéria fresca. A matéria seca de tubérculos foi determinada em uma amostra de 10 tubérculos, representativa do tratamento, a qual foi secada em estufa de circulação forçada de ar, da mesma forma 
como para os demais órgãos. Também foi determinada a matéria seca média de tubérculos.

Os dados foram submetidos à análise de variância pelo teste $\mathrm{F}$. As médias com diferenças significativas entre os tratamentos foram comparadas pelo teste Tukey $(\alpha=0,05)$ ou submetidas ao ajuste de modelos de regressão não linear, conforme o caso.

\section{RESULTADOS E DISCUSSÃO}

O aumento do IAF com o aumento da densidade de plantio foi assintótico, ajustando-se a um modelo exponencial negativo (Figura 1). O valor mínimo do IAF foi de $6,5 \mathrm{~m}^{2} \mathrm{~m}^{-2}$, na densidade de 25 covas $\mathrm{m}^{-2}$, e o máximo foi de $19 \mathrm{~m}^{2} \mathrm{~m}^{-2}$, na densidade de 400 covas $\mathrm{m}^{-2}$. A tendência de saturação da resposta evidenciou-se a partir da densidade de 100covas $\mathrm{m}^{-2}$, pois o IAF aumentou apenas $15 \%$ dessa densidade até a de 400covas $\mathrm{m}^{-2}$. Os valores de IAF observados nas quatro densidades foram mais elevados do que aqueles medidos em lavouras de batata, os quais se situam em valores máximos próximos a $6 \mathrm{~m}^{2} \mathrm{~m}^{-2}$ (WRIGHT \& STARK, 1990). Embora os valores de IAF não tenham diferido nas densidades de 100 covas $\mathrm{m}^{-2}$ e 400covas $\mathrm{m}^{-2}$, esta última induziu mortalidade a $55 \%$ das plantas, enquanto que as demais densidades apresentaram mortalidades similares, em torno de $25 \%$. Uma taxa moderada de mortalidade de plantas é esperada nesse sistema de multiplicação de minitubérculos, provocada pela heterogeneidade na fase inicial da brotação dos minitubérculos. Aqueles tubérculos que se encontram em dormência ou com dominância apical tardam a emergir e as plantas sofrem uma alta competição intraespecífica com as mais vigorosas. À medida que prossegue o crescimento do IAF e que a quantidade de radiação absorvida pelas plantas mais retardadas em crescimento torna-se inferior ao respectivo limite trófico, essas plantas entram em senescência precoce e morrem (CASTRO et al., 1987). A mortalidade de mais de $50 \%$ das plantas, na maior densidade de plantio, a torna inadequada à produção comercial de minitubérculos porque representa uma perda excessiva de material propagativo.

O IAF de $19 \mathrm{~m}^{2} \mathrm{~m}^{-2}$ na densidade de 400 covas $\mathrm{m}^{-2}$ é surpreendente porque se situou múltiplas vezes acima daquele considerado ótimo para a cultura da batata. Foi demonstrado que, em cultivo de batata em campo, cerca de $95 \%$ da radiação solar incidente é absorvida com valores de IAF entre 3 e $4 \mathrm{~m}^{2}$ $\mathrm{m}^{-2}$ (KHURANA \& McLAREN, 1982; ANDRIOLO et al., 2006). Os elevados níveis de IAF observados devemse tanto à distribuição espacial homogênea do material propagativo no leito de cultivo no momento do plantio, como à reduzida força de dreno dos tubérculos na fase inicial do crescimento e desenvolvimento da cultura. Nessa fase, a maior parte dos assimilados produzidos

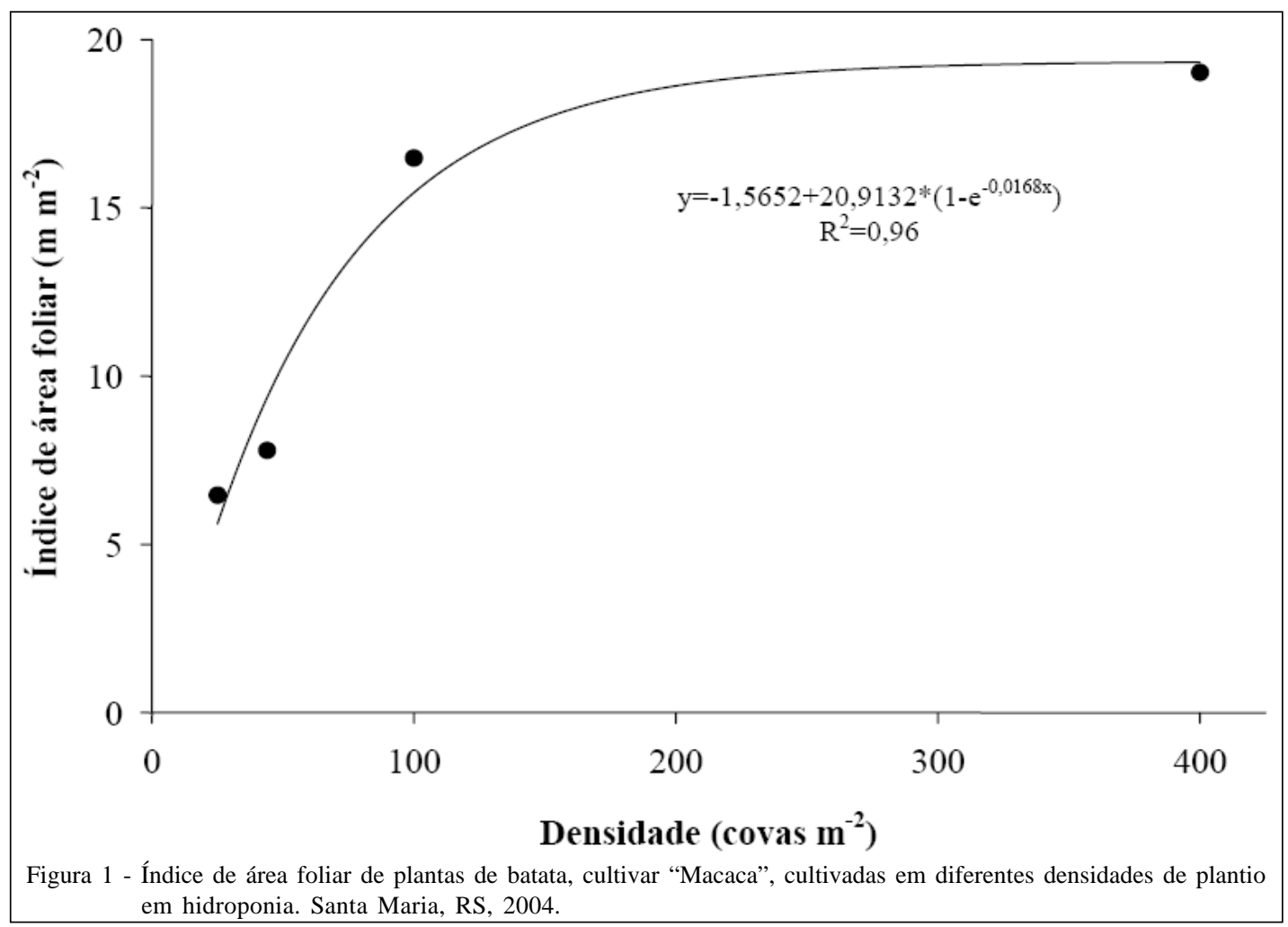

Ciência Rural, v.38, n.6, set, 2008. 
pela fotossíntese é alocada para o crescimento vegetativo das plantas. Essa situação passa a alterarse após o início da tuberização. Caso o período de cultivo não fosse interrompido pela colheita dos tubérculos e estes fossem deixados a exercer o potencial de crescimento, é provável que ocorresse um aumento progressivo na mortalidade das plantas, reduzindo o IAF na fase final do período de crescimento dos tubérculos a níveis próximos daqueles observados nas lavouras.

A produção de matéria seca total e vegetativa aumentou também assintoticamente com o aumento da densidade de plantio e também ajustou-se a um modelo exponencial negativo, com tendência de saturação da resposta a partir da densidade de 100covas $\mathrm{m}^{-2}$ (Figura 2). Diferenças significativas entre as médias do crescimento dos tubérculos nas diferentes densidades de plantio, não foram observadas e apresentou produção média de matéria seca de $495 \mathrm{~g} \mathrm{~m}^{-2}$. A saturação da resposta do crescimento vegetativo com o aumento da densidade de plantio é conseqüência da saturação do IAF, uma vez que a radiação solar absorvida é a primeira variável determinante do potencial de crescimento vegetal (CASTRO et al., 1987; EWERT, 2004). Esse resultado confirma a formalização empregada pelos modelos de crescimento das culturas agrícolas, nos quais a fração absorvida da radiação solar é uma das principais variáveis de entrada (HEUVELINK, 1996; ROSATI et al., 2001). Confirma também o enfoque das relações de competição entre plantas dentro de uma cobertura vegetal baseado na isometria entre o crescimento dos diferentes órgãos, com a morte daquelas nas quais as relações de alometria entre as taxas de crescimento desses órgãos não são mais possíveis de serem mantidas (THORNLEY, 1998). Modelos exponenciais foram ajustados para o número e a matéria seca média dos tubérculos para as diferentes densidades de plantio (Figura 3). O número de tubérculos apresentou resposta crescente assintótica com o aumento da densidade de plantio, enquanto que para a matéria seca média a resposta foi decrescente. A diminuição da matéria seca média do tubérculo com o aumento do número por unidade de área é conseqüência da competição pelos assimilados. Uma relação inversa entre número e matéria seca média do tubérculo foi confirmada nas três densidades mais baixas. Entretanto, ao passar da densidade de 100 para 400 covas $\mathrm{m}^{-2}$ o número de tubérculos aumentou $79 \%$, enquanto que a matéria seca média diminuiu apenas $46 \%$. Essa diferença pode estar relacionada com a emissão dos novos tubérculos nas plantas de batata. A demanda por assimilados em órgãos de reserva segue tendência exponencial nas fases que se seguem à multiplicação celular (BERTIN, 2005). Isso significa que a competição pelos assimilados ainda é baixa no período inicial do crescimento, quando os tubérculos são ainda pequenos, e aumenta posteriormente. Essa hipótese pode explicar a diferença observada, uma vez que o

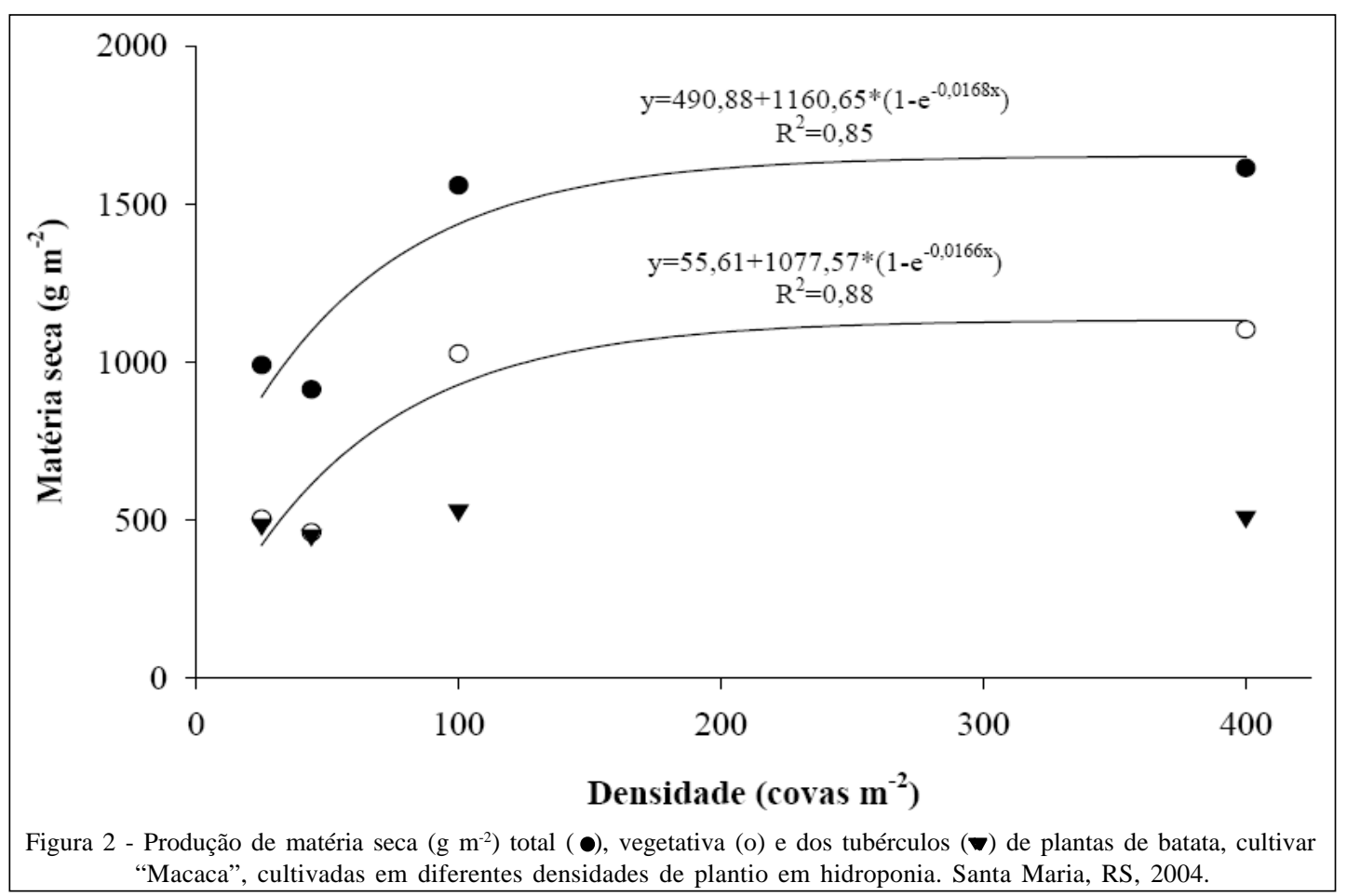

Ciência Rural, v.38, n.6, set, 2008. 


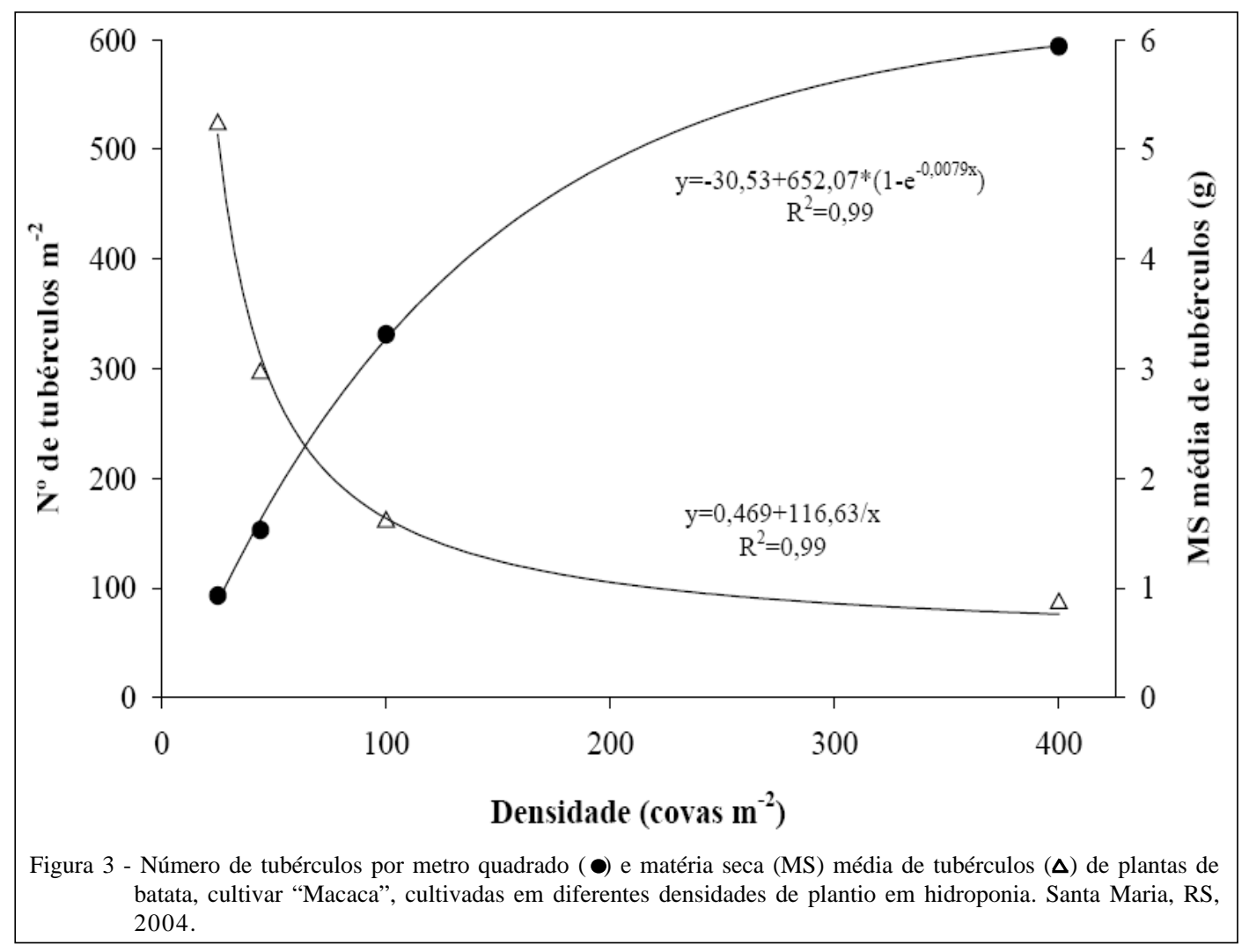

elevado número de tubérculos na densidade de 400covas $\mathrm{m}^{-2}$ deveu-se, principalmente, ao grande número daqueles de pequeno tamanho. Esses tubérculos pequenos somente acentuaririam a competição pelos assimilados nas fases posteriores de crescimento, caso a colheita fosse postergada. Entretanto, tubérculos muito pequenos são pouco adequados ao uso como material propagativo devido à facilidade de desidratação, ao baixo número de gemas e à reduzida reserva de carbono, que dificultam a emergência e reduzem o vigor das plântulas (McKEOWN, 1990; KAWAKAMI et al., 2004).

Os resultados deste trabalho mostram que o aumento da densidade de plantio de 25 para 100covas $\mathrm{m}^{-2}$ aumenta o IAF e a matéria seca total, sem afetar a produção de matéria seca de tubérculos $\left(\mathrm{g} \mathrm{m}^{-2}\right)$. Apesar de não afetar a matéria seca de tubérculos, o adensamento das plantas aumenta o número de tubérculos por área e, como conseqüência, reduz a matéria seca média dos mesmos. Portanto, densidades mais elevadas de plantio podem ser utilizadas para aumentar a taxa de propagação, pois um maior número de tubérculos de menor tamanho são produzidos. No entanto, densidade muito alta não deve ser utilizada devido ao aumento do IAF, que, por sua vez, aumenta o consumo de solução nutritiva, exige estruturas de suporte para evitar o acamamento e dificulta a circulação de ar no dossel, favorecendo a incidência de doenças. Portanto, a densidade de plantio de 100covas $\mathrm{m}^{-2}$ proporciona a melhor combinação de número de minitubérculos por área e matéria seca média dos mesmos. Além disso, o experimento foi conduzido durante a primavera, quando as temperaturas mais elevadas promovem o crescimento da parte aérea em detrimento dos tubérculos e ocorre uma redução da fotossíntese líquida, devido ao aumento da respiração (FONTES \& FINGER, 1999). No cultivo de outono, ocorre uma menor produção de matéria seca da parte aérea, com um menor IAF, o que favoreceria ainda mais a utilização da densidade de 100 covas $\mathrm{m}^{-2}$, uma vez que nesse sistema hidropônico o IAF no cultivo de outono foi $50 \%$ menor do que o alcançado na primavera (MÜLLER et al., 2007).

\section{CONCLUSÃO}

Para a produção de minitubérculos de batata no sistema hidropônico fechado com o uso de areia grossa como substrato, deve ser utilizada a densidade de plantio de 100 covas $\mathrm{m}^{-2}$ por proporcionar a melhor combinação de número de minitubérculos por área e matéria seca média.

Ciência Rural, v.38, n.6, set, 2008. 


\section{AGRADECIMENTOS}

Ao Conselho Nacional de Desenvolvimento Científico e Tecnológico (CNPq), pela Bolsa de Produtividade em Pesquisa a Dilson Antônio Bisognin, Jerônimo Luiz Andriolo e Nereu Augusto Streck. À Coordenação de Aperfeiçoamento de Pessoal de Nível Superior (CAPES), pela Bolsa de Mestrado a Jacso Dellai.

\section{REFERÊNCIAS}

ANDRIOLO, J.L. Fisiologia das culturas protegidas. Santa Maria: UFSM, 1999. 142p.

ANDRIOLO, J.L. Sistema hidropônico fechado com subirrigação para produção de minitubérculos de batata. In: SIMPÓSIO DE MELHORAMENTO GENÉTICO E PREVISÃO DE EPIFITIAS EM BATATA, 2006, Anais... Santa Maria: UFSM, CCR, Departamento de Fitotecnia, 2006. p.26-40.

ANDRIOLO, J.L. et al. Curva crítica de diluição do nitrogênio da cultivar "Asterix" de batata. Pesquisa Agropecuária Brasileira, v.41, n.7, p.1179-1184, 2006.

BENINCASA, M.M.P. Análise de crescimento das plantas. Jaboticabal: FUNEP, 1988. 42p.

BERTIN, N. Analysis of the tomato fruit growth response to temperature and plant fruit load in relation to cell division, cell expansion and DNA endoreduplication. Annals of Botany, v.95, p.439-447, 2005.

CASTRO, P.C.R. et al. Ecofisiologia da produção agrícola. Piracicaba: Associação Brasileira para Pesquisa da Potassa e do Fosfato, 1987. 249p.

EWERT, F. Modelling plant responses to elevated $\mathrm{CO}_{2}$ : how important is leaf area index? Annals of Botany, v.93, p.619627, 2004.

FONTES, P.C.R.; FINGER, F.L. Dormência dos tubérculos, crescimento da parte aérea e tuberização da batateira. Informe Agropecuário, v.20, n.197, p.24-29, 1999.

HEUVELINK, E. Dry matter partitioning in tomato: validation of a dynamic simulation model. Annals of Botany, v.77, p.71-80, 1996.
HUTCHINGS, M.J.; JOHN, E.A. The effects of environmental heterogeneity on root growth and root/shoot partitioning. Annals of Botany, v.94, p.1-8, 2004.

KAWAKAMI, J. et al. Effect of cultivar maturity period on the growth and yield of potato plants grown from microtubers and conventional seed tubers. American Journal of Potato Research, v.81, p.327-333, 2004.

KHURANA, S.C.; McLAREN, J.S. The influence of leaf area, light interception and season on potato growth and yield. Potato Research, v.25, n.4, p.329-342, 1982.

McKEOWN, A.W. Growth of early potatoes from different partions of seed tubers 1. Emergence and plant stand. American Potato Journal, v.67, p.751-759, 1990.

MEDEIROS, C.A.B. et al. Produção de sementes pré-básicas de batata em sistemas hidropônicos. Horticultura Brasileira, v.20, n.1, p.110-114, 2002.

MULLER, D.R. et al. Produção hidropônica de batata em diferentes concentrações de solução nutritiva e épocas de cultivo. Pesquisa Agropecuária Brasileira, v.42, p.647-653, 2007.

PAPADOPOULOS, A.P.; PARARAJASINGHAM, S. The influence of plant spacing on light interception and use in greenhouse tomato (Lycopersicon esculentum Mill.): a review. Scientia Horticulturae, v.69, p.1-29, 1997.

RITTER, E. et al. Comparison of hydroponic and aeroponic cultivation systems for the production of potato minitubers. Potato Research, v.44, n.2, p.127-135, 2001.

ROSATI, A. et al. Estimating canopy light interception and absorption using leaf mass per unit leaf area in Solanum melongena. Annals of Botany, v.88, p.101-109, 2001.

SEGINER, I. Equilibrium and balanced growth of a vegetative crop. Annals of Botany, v.93, p.127-139, 2004.

THORNLEY, J.H.M. Modelling shoot:root relations: the only way forward? Annals of Botany, v.81, p.165-171, 1998.

WRIGHT, J.L.; STARK, J.C. Potato. In: STEWART, B.A.; NIELSEN, D.R. (Eds.). Irrigation of agricultural crops. Madison: American Society Agronomy, 1990. p.859-888. 